\title{
Writing the Future. Prognostic Texts of Medieval England, T. Hunt (ed.)
}

\section{G. Matteo Roccati}

\section{Q OpenEdition}

1 Journals

\section{Édition électronique}

URL : http://journals.openedition.org/studifrancesi/9885

DOI : 10.4000/studifrancesi.9885

ISSN : 2421-5856

Éditeur

Rosenberg \& Sellier

\section{Édition imprimée}

Date de publication : 1 août 2017

Pagination : 332-333

ISSN : 0039-2944

\section{Référence électronique}

G. Matteo Roccati, «Writing the Future. Prognostic Texts of Medieval England, T. Hunt (ed.) », Studi Francesi [En ligne], 182 (LXI | II) | 2017, mis en ligne le 18 octobre 2017, consulté le 12 janvier 2021. URL : http://journals.openedition.org/studifrancesi/9885; DOI : https://doi.org/10.4000/studifrancesi. 9885

Ce document a été généré automatiquement le 12 janvier 2021.

\section{(c)}

Studi Francesi è distribuita con Licenza Creative Commons Attribuzione - Non commerciale - Non opere derivate 4.0 Internazionale. 


\title{
Writing the Future. Prognostic Texts of Medieval England, T. Hunt (ed.)
}

\author{
G. Matteo Roccati
}

\section{RÉFÉRENCE}

Writing the Future. Prognostic Texts of Medieval England, edited by Tony HUNT, Paris, Classiques Garnier, 2013, «Textes littéraires du Moyen Âge» 24, Série Divinatoria 2, 360 pp.

1 Le volume rassemble la première édition d'une cinquantaine de «written guides to prognostication or prediction» (p. 14), notamment des lunaires, les plus développés, en anglo-normand, latin et moyen-anglais. Ils sont contenus dans un petit nombre de manuscrits, dont les plus importants sont présentés brièvement dans l'introduction (Oxf., Bodl. Libr. Ashmole 304, et Digby 46; Lyell 36; London, Brit. Libr. Add. 15236; Cambr., Univ. Libr. GG 1.1.; Yale, Beinecke Libr. 395; Oxf., Bodl. Libr. Ashmole 342 et 345; Cambr., Corpus Christi Coll. 37). Sept chapitres suivent, chacun consacré à une forme: I: Prose Lunaries; II: Verse Lunaries; III: Zodiacal 'I'reatises; IV: Observation of Times (Nativities, Meteorological Prognostics, Brontologies (Thunderbooks, "Tonitrualia"), Wind Prognostics, Perilous Days, Health Regimens (Diet), Prognostics according to Dominical Letters); V: Oneiromancy; VI: Books of Fate; VII: Geomancy. Chaque chapitre comporte un glossaire sélectif. Bibliographie aux pp. 335-345, index des manuscrits, des textes et des matières aux pp. 347-349, 351-353, 355-356. 